\title{
A WHOLE LOTTA FOCUSIN' GOIN' ON: INFORMATION PACKAGING IN SOMALI TEXTS *
}

\author{
Mauro Tosco \\ Istituto Universitario Orientale
}

\begin{abstract}
The article deals with the pragmatics of focus marking in Somali written texts. The use of the nominal focus markers baa and ayaa, of clefts, of noun incor-poration and of the particle waa is analyzed. Concerning the latter, it is argued that the verbal-focus effect often associated with it is more the result of the absence of nominal focus than an inherent property of this particle, thereby confirming Saeed's analysis of waa as a "declarative classifier". A few text-building uses of the focus particles are discussed, namely, the use of subject focus in text-initial thetic sentences, the topic-shifting value of nominal focus, and the use of focus on a clausal or nominal adverbial as an action-enhancing device. In light of these considerations, it is argued that the nominal focus particles are perhaps better considered as generic "foregrouding particles".
\end{abstract}

\section{Introduction}

The grammar of focus is without a doubt the single most studied feature of Somali syntax. Due to the painstaking efforts of a number of scholars, starting with Andrzejewski [e.g., 1964, 1975] and followed by Puglielli [e.g., 1981] and her associates in Rome [e.g., Svolacchia, Mereu \& Puglielli 1995], John I. Saeed [e.g., 1984, 1999] and J. Lecarme [e.g., 1994], we have gained a fairly finegrained knowledge (generally couched within a generative, either GB or minimalist, framework) of the syntactic conditionings which regulate focus marking.

Briefly, and leaving aside the intricacies of subject marking and verb form when associated with focus, the following general rules apply:

\footnotetext{
* This article was written during my stay at the Institut für Sprachwissenschaft of the University of Cologne (March-October 2002), which was made possible by a scholarship from the Alexander von Humboldt Foundation. I want to thank Cabdulqaadir Salaad Dhoorre for his help and insights in analyzing the Somali material. I also thank Hans-Jürgen Sasse and two anonymous referees of Studies in African Linguistics for their comments and criticisms. Obviously, all errors and omissions are exclusively mine.
} 
1. any main declarative (positive) sentence must receive focus marking (except for 5. below);

2 . in any sentence, only one NP may receive focus, marked by the nominal focus marker baa or ayaa which follows the last member of the NP or is cliticized to it;

3. apart from the focused phrase, all the other nominal elements (with the exception of incorporated ones; cf. below Section 8.) may be considered topics;

4. the order of constituents is syntactically free, and all the grammatical information is found within the "Verbal Complex", which contains in rigid order object pronouns, adpositions and adverbials and is ended by the verbal form;

5. whenever an NP is not focalized, a main declarative sentence is marked by waa, which is either described as a "verbal focus marker" [e.g., Puglielli 1981] or as a "declarative sentence marker" [Saeed 1984, 1999];

6. all other sentence types (dependent, negative, interrogative, imperative, etc.) are not focus-marked;

7. apart from the nominal focus and waa, a cleft construction is frequently used, whereby a constituent may be shifted to the right of the verb.

In contrast to syntax, the pragmatic and discourse conditioning of focus have received much less attention; among the very few studies dealing with the pragmatics of Somali sentences, one can mention Hetzron [1965], El-Solami-Mewis [1980, 1981], and, in particular, Gebert [1986]. As a consequence, attention has been brought upon the conditions for the placement of "narrow" focus and the order of topical NPs within the sentence (an issue which will not be dealt with here, and for which the interested reader may consult Gebert [1986]), but, with the possible exception of Ajello [1995], larger-than-the-sentence units have hardly been considered at all.

In contrast to this sentence-centered approach, the present article will look at the interplay of nominal focus (through baa or ayaa), the element waa and clefting in the information packaging of Somali texts. It will be shown that, apart from the use of the nominal focus markers baa or ayaa in "narrow" (argument) focus, subject focus is used textually in event-reporting sentences, i.e., whenever the whole sentence is pragmatically new, and in thetic (presentational) sentences. Further textual-based uses of focus involve the focusing of an adverbial (either an NP or a subordinate clause) as an "action-enhancing" strategy, and the use of clefts. In contrast, the use of the element waa seems to be linked with the absence of focus and the backgrounding of topical elements. Apart from its mandatory use in focusless nominal sentences and in focusless, not-event-reporting and notthetic intransitive sentences, waa will therefore be found whenever the attention is brought upon the action itself, and all the other elements are detopicalized, as is frequently the case when a noun is incorporated into the verb.

Although our analysis is based upon a very limited corpus (basically, Ciise's [1985] collection of Somali folktales, as well as a selection of articles from a few Somali websites), the information-packaging strategies identified are very robust: they recur in a large number of cases, and some of them (such as the use of 
subject focus in thetic sentences) are commonplace in any Somali text. Moreover, they find their parallel in many other languages. What is peculiar to Somali is rather the use to these purposes of those ubiquitous elements which mark most Somali main declarative sentences: the focus markers.

\section{Subject focus and event-reporting sentences}

It will be assumed, following Lambrecht [1994], that the division of sentences into topic and comment is a universal feature of sentence organization, with topic loosely defined as "the referent about which the proposition is construed, expressing information which is relevant to and which increases the addressee's knowledge of this referent" [cf. Lambrecht 1994:131], while focus is simply "[T]he semantic component of a pragmatically structured proposition whereby the assertion differs from the presupposition" [Lambrecht 1994:213]. Therefore, the overall function of focus marking is "to indicate denotata with pragmatically nonrecoverable relations to propositions, whether topical or focal" [Lambrecht 1994:337].

It will also be assumed that the presence of lexical and morphosyntactic marking of pragmatic functions in Somali and many other East Cushitic languages finds its ultimate explanation in the non-availability for pragmatic purposes of sentence accent in pitch-accent languages, in which accent is used for morphosyntactic and lexical coding. A similar conclusion was reached by Sasse [1984: 266, fn. 16]: "One motivation for the development of such an elaborate focusmarking system may perhaps be seen in the fact that, in the course of the history of EC [:East Cushitic; MT] languages, there has been a considerable increase in the distinctive functions of pitch differences (tone). This may have given rise to the avoidance of intonational means of pragmatic marking and their replacement by morphosyntactic means'.

At the same time, Somali, like many verb-final languages, does not have access to subject inversion as frequently found in Romance languages. Information structure therefore needs a different coding.

Even a cursory look at a Somali text reveals that the particles baa and ayaa are employed with a variety of constituents which it would be very difficult to qualify as "in focus" on either semantic or pragmatic grounds. As has been noted by Gebert [1986:48], (2) could be uttered as a reply to (1). ${ }^{1}$

${ }^{1}$ Somali examples are in the standard orthography, in use since 1972. Its main peculiarities are: $\langle\mathrm{c}\rangle=[\mathrm{G}] ;\langle\mathrm{x}\rangle=[\mathrm{h}] ;\langle\mathrm{dh}\rangle=[\mathrm{d}]$. The following abbreviations are used in the glosses:

ANPH anaphoric article

ART determinate article

DEP dependent mood

$F$ feminine

FOC 1. nominal focus marker;

2. subject-focus verbal form

GEN genitive case form

IMP impersonal subject pronoun

INF infinitival verbal form
ITIV itive adverb (sii): movement away from the speaker or the center of attention

LINK linking particle (ee), used with appositive relatives and in modifying a definite head

M masculine

NEG 1. negative particle;

2. negative verbal form 
(1) Maxaa dhacay?

what happen.PAST.3M.FOC ${ }^{2}$

'What happened?'

(2) Cali baa Maryam dilay

Cali FOC Maryam beat.PAST.3M.FOC

'Cali beat Maryam'

Obviously, here not just the subject Cali, but the whole sentence is new and asserted. Gebert notes that a sentence in which waa, rather than baa, is used (e.g., Cali Maryam wuu dilay, in which wuu is the element waa followed by the clitic subject pronoun -uu; see also Section 9 below), though syntactically wellformed, would hardly be appropriate, and that Somali speakers have difficulties in producing and accepting such sentences. What is missing from Gebert's analysis is a unified theory of focus. Using Lambrecht's [1994] tripartite division of focus structures into predicate, argument, and sentence focus, a sentence like (2) will be an instance of sentence focus. The fact that the whole proposition is asserted does not mean that the focus of the assertion does not cover the subject, which is the element marked as focused in Somali: it does, but together with the whole sentence, whose pragmatic presupposition is simply that something happened. Contrary to topic-comment sentences, in (2) Cali is not the topic (although of course it must be identifiable to the addressee) and the sentence is not a statement about him: (2) is an event-reporting sentence, a sentence which could also be uttered "out of the blue" [Lambrecht 1994:124]. Such sentences are marked in English primarily by accent on the subject (accompanied, in transitive sentences, by accent on the object: 'CALI beat MARYAM'), prosodically the reverse of topiccomment sentences ('Cali beat MARYAM'). The same reversal of the topiccomment pattern is instead realized syntactically in various Romance languages through subject inversion. In a topic-comment sentence, the focus is on the predicate (in the sense of "what is predicated about the subject", i.e., the verb together with the object and, where relevant, other "new" elements. In English the absence of prosodic prominence on a constituent indicates the active (topical) status of its referent, while the presence of prominence is compatible with either an inactive or an active status [Lambrecht 1994:98]; an active element may well get accent and still be topical. In Somali, absence of focus marking only indicates that the referent is active, while the presence of focus is neutral with respect to

\begin{tabular}{|c|c|c|c|}
\hline $\mathrm{P}$ & plural & $S$ & singular \\
\hline PAST & past tense & SUBJ & subject case \\
\hline PRES & present tense & VENT & ventive adverb ( $\mathrm{SOO}$ ): movement \\
\hline $\begin{array}{l}\text { PROG } \\
Q\end{array}$ & $\begin{array}{l}\text { progressive } \\
\text { question marker }\end{array}$ & & $\begin{array}{l}\text { toward the speaker or the center of } \\
\text { attention }\end{array}$ \\
\hline REFL & reflexive object pronoun & VN & verbal noun \\
\hline
\end{tabular}

2 When the focused element is the subject, the verb has a special tonal pattern as well as a special reduced accord; such forms are glossed here with FOC, although no pragmatic focus on the verb is implied. 
this feature and can be used both with active and inactive referents: in many cases focus is found on a topical element, as in the case of contrastive focus, while in other cases focus will mark a new constituent.

According to Lambrecht [1994], there are therefore three focus possibilities, realized prosodically in English by two basic accent-sentence patterns (in the following scheme, accent is indicated by small caps):

Predicate focus: 'Cali BEAT MARYAM' (topic — PREDICATE)

Argument (subject) focus: 'CALI beat Maryam' (TOPIC — predicate)

Sentence focus:

'CALI beat Maryam' (PREDICATE)

In English, sentence focus is not unambiguously marked: the same sentence pattern is used in the case of argument focus on the subject, as in answering the question 'who beat Maryam?' Likewise, in Somali a sentence like (2) is ambiguous between a sentence-focus interpretation and an argument focus interpretation; sentence (3) could again be answered by (4), identical to (2).

Yaa Maryam dilay?

who Maryam beat.PAST.3M.FOC

'Who beat Maryam?'

(4) Cali baa Maryam dilay

Cali FOC Maryam beat.PAST.3M.FOC

'CALI beat Maryam'

Moreover, the same construction with subject-focus marking would be used in the case of contrastive focus: sentence (5) could be answered by (6), identical again to (2). As noted by Lambrecht [1994:286], "contrastiveness" is better understood as a gradient property of narrow focus, with no specific marking. The absence of a specific construction which would mark the subject of (6) as a reply to (5) is therefore totally expected.

(5) Ma Cali mise Axmed baa Maryam dilay?

Q Cali or Axmed FOC Maryam beat.PAST.3M.FOC

'Was it Cali or Axmed who beat Maryam?'

(6) Cali baa Maryam dilay

Cali FOC Maryam beat.PAST.3M.FOC

'CALI beat Maryam'

Leaving aside the complex issue of the position of the non-focused object NP Maryam in (2), it is important to note that the Somali data confirm Lambrecht's [1994:321] observation that "[P]artial or total homophony of sentence-focus and narrow-focus sentences is a common occurrence across languages".

The first rule for the information packaging of a Somali text is therefore: "event-reporting sentences are expressed through focus marking on the subject NP". 


\section{Subject focus and thetic sentences}

There are no presentational particles in Somali, neither is subject inversion, of the type commonly found, e.g., in Romance, available. Thetic judgements make use instead of subject focus marking, as in (7)-(8). Of course, this construction is one and the same with the subject-focus-marking sentences seen above. For example, (8) could also be used for narrow focus on the subject, as in answering (9).

(7) roob baa da'aya rain FOC fall.PROG.3M.FOC

'It is raining'

(8) Cali baa imanaya

Cali FOC come.PROG.PRES.3M.FOC

'Cali is coming'

(9) yaa imanaya?

who come.PROG.PRES.3M.FOC

'Who is coming?'

Thetic sentences are often found at the beginning of a text (cf. also below Section 5), as in (10) and (11), the initial sentences from two folktales.

(10) laba nacas baa waa $^{3}$ is qabay two fool FOC time REFL take.PAST.3M.FOC

'There were once two fools married to each other' [Ciise 1985:73]

(11) laba nin baa waa ollog ahaa two man FOC time neighbor be.PAST.3M.FOC

'There were once two neighbors' [Ciise 1985:49]

At the same time, not all instances of initial subject focus are thetic; many are simply event-reporting; consider (12), from a tale in which a man and a lion become friends. The sentence in (13), instead, is the opening line of a newspaper article.

(12) Libaaxii baa dabadeed kexeeyay oo gurigiisii lion=M.ANPH FOC then lead.PAST.3M.FOC and house=M.his.ANPH

geeyay

take.PAST.3M.FOC

'After that the lion took him and brought him to its den' [Ciise 1985:67]

3 waa here is a noun meaning 'time' and has a different tonal pattern from the classifier waa. 
(13) Ciidanka booliska ee saldhigga Berbera ayaa force $=$ M.ART police $=$ M.ART LINK station=M.ART Berbera FOC shalay gacanta ku dhigay haweeney soo xadday yesterday hand=F.ART to put.PAST.3M woman VENT steal.PAST.3F cunug da'diisu ahayd 10 bilood infant age $=$ M.his.SUBJ be.PAST.3F 10 month.GEN

'Yesterday police forces of the Berbera [police] station caught a woman who had kidnapped a 10-month-old infant' (www.ayaamaha.com/News/April10217/N005.html)

In other languages this sentence would be built as a topic-comment structure with a major sentence stress on the object NP in English (cf. the hardly acceptable English rendering of (13) with 'FORCES OF THE BERBERA POLICE STATION caught...'). Somali has recourse instead to subject focus. Note also that the focused element (in this case, the subject phrase) is not the one which is going to be the "center of attention": the text is not "built around" the police. In fact, the next sentence in the text is (14).

Cunuggii iyo haweeneydii ayaa la sheegay in infant=M.ANPH and woman=F.ANPH FOC IMP say.PAST.3M that haatan lagu hayo saldhigga Berbera now IMP=in hold.DEP.3M station=M.ART Berbera

'It is reported that the infant and the woman are presently kept at the Berbera police station' (www.ayaamaha.com/News/April10217/N005.html)

In other cases subject-focus has a contrastive value and is therefore to be analyzed as an instance of argument focus; this is often the case when an NP changes its syntactic role from subject to object or vice versa. In (15) a man finds a leopard sleeping along the road and, thinking it to be dead, makes ready to skin it; the leopard is introduced in the role of object. At the last moment, the leopard stands up and slays the unfortunate man (16). The leopard, which is obviously topical, now becomes the syntactic subject, and is marked by focus.

(15) Isagoo iska mushaaxaya ayuu maalin kale shabeel he=and REFL=in stroll.PROG.PRES.FOC FOC=he day other leopard waddada dhex hurda ka dul dhacay road=F.ART middle sleep.PRES.FOC on upon happen.PAST.3M 'Another day, strolling around, he came by a leopard sleeping in the middle of the road' [Ciise 1985:69] 
(16) Shabeelkii baase ku toosay oo meeshii ku leopard=M.ANPH FOC=but in stand-up.PAST.3M and place=F.ANPH in

kala gooyay

apart cut.PAST.3M

'But the leopard stood up and and slayed him on the spot' [Ciise 1985:69]

In (17), from another text, a jackal tricks a lion into eating a stone wrapped in resin. The lion, which is the indirect object of the preceding sentence and which is topical, then becomes the subject and is again marked by focus.

(17) ... debadeedna ${ }^{4}$ dhagaxii xabagtu ka dahaarreyd then=and stone=M.ANPH resin=F.ART.SUBJ in covered.PAST.3F hoosta $u$ gelisey underneath=F.ART to enter.CAUS.PAST.3F

'... then she 5 slipped the stone wrapped in resin under him' [Ciise 1985:75]

(18)

Libaaxii baa xabagtii laq is yiri 6 lion=M.ANPH FOC resin=F.ANPH laq REFL say.PAST.3M 'The lion wolfed down the resin' [Ciise 1985:75]

In all these cases, the function of the focus marker can therefore be said to be simply that of a topic-switching device.

\section{Object focus: focus marking as a topic-switching device}

Subject-focus, although fairly frequent, especially text-initially, is obviously not the only possibility; object-focus is the normal way to introduce a new element in a text. In (19) we see the same non-coextensiveness of the syntactic and pragmatic domains of focus marking seen in Sections 2. and 3. for subject focus. As noted by Gebert [1986:46], the sentence in (2) above, with subject focus, is excluded precisely if the subject is already activated, as in (20), which could be answered by (21).
(19) ... hal
gool ah beyna
heleen
she_camel fat be FOC=they=and find.PAST.3P
'... and they found a fat she-camel' [Ciise 1985:63]

4 Most probably a typographical error for dabadeedna.

5 'Jackal' (dawaco) is grammatically Feminine.

6 laq is an ideophone expressing the action of swallowing. 
(20) Cali muxuu sameeyay?

Cali.SUBJ 7 what=he do.PAST.3M

'What did Cali do?'

(21) Cali Maryam buu dilay

Cali.SUBJ Maryam FOC=he beat.PAST.3M

'Cali beat Maryam'

In (21) baa focalizes the object Maryam, although not only Maryam, but also her beating, are new. Just as for (2) in Section 2 above, the sentence in (21) shows that focus on an NP may contain focus on the predicate: focus on the subject (cf. (2)) presupposes pragmatic focus on the whole sentence, while focus on the object (cf. (21)) presupposes pragmatic focus on the whole predicate, or the VP, although a syntactic VP category does not exist in Somali. Object-focus is therefore used either for a "broad" focus on the whole predicate, as in topiccomment sentences such as (21), or for a "narrow" argument focus. Consider the question (22).

(22) Cali yuu dilay?

Cali.SUBJ who=he beat.PAST.3M

'Whom did Cali beat?'

Although the most probable spontaneous answer to (22) would simply be Maryam, an appropriate sentential answer would involve both the use of the focus particle and the shift of the whole focused object NP before the subject.
Maryam baa Cali dilay
Maryam FOC Cali.SUBJ beat.PAST.3M
'It was Maryam whom Cali beat'

Just as a topical subject can get focus, one often finds focus used with a topical object; (19) is immediately followed in the text by (24).

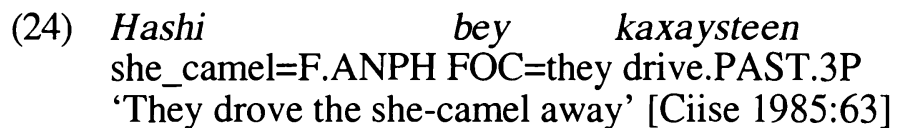

In (24) the she-camel, which has already been introduced in (19) and is therefore active, is still focus-marked. The value of focus marking in this context can best be understood as that of a topic-switching device: after having introduced in the preceding sentences the protagonists of the story, now the discourse is centered on the she-camel and its fate.

7 Subject is expressed here (as on most nouns) tonally through absence of high tone; i.e., Cali (Absolute case form: [Yáli]) vs. Cali (Subject case form: [Yali]). Tone is not represented in the standard orthography. 
The value of focus marking as a topic switch is also evident in another tale, which begins with (25), the usual thetic sentence with subject focus. The text continues with (26).

(25) Nin baa waa ari badan lahaa

man FOC time sheep many have.PAST.3M

'Once a man had many sheep', or

'There was once a man who had many sheep' [Ciise 1985:65]

(26) Arigii baa cudur xumi ka galay

sheep=M.ANPH FOC disease bad.SUBJ in enter.PAST.3M

'A bad disease fell upon the sheep', or

'The sheep fell prey to a bad disease' [Ciise 1985:65]

Note that in (26) it is the object "the sheep" which gets focus, and not the subject, which is new. Although the sheep is not a new element, while the disease is, the sheep are the center of attention; actually, in the text the disease will not be further mentioned, while the attention will be brought upon its consequences, and (27), the third sentence of the text reverts to subject focus.

... maalin kastana dhowr neef baa ka dhiman jirtay 8 day each=and several animal FOC from die.INF exist.PAST.3F.FOC '... and every day many animals died' [Ciise 1985:6]

Although thetic sentences, argument focus, and topic shift account for many instances of focus marking, neither the subject nor the object are the most common bearers of focus marking in a Somali text: rather, whenever they are present either an adverbial or a subordinate clause are the preferred locus of focus. To this we turn in the following section.

\section{Adverbial focus: focus marking as an action-enhancing device}

Having set the scene and presented the participants, the tale of the sheep continues with the actual action: the shepherd divides his flock into two parts, one for himself and the other for God, asking God to take His part and let him keep the rest. But, as the epidemic goes on, he starts killing one sheep from God's flock whenever one of his sheep dies.

As the action develops, the normal solution is to focalize an adverbial, be it a nominal phrase or a whole clause. After (27), the fourth sentence of the text is (28). This pattern, in which a time or manner adverbial or a dependent clause gets focus, is preserved for all the following text.

8 An Infinitival verbal form followed by the Past of the verb jir 'to exist' expresses the Habitual Past. 
(28) Goor arigii sii daba yar yahay, buu laba u time sheep=M.ANPH ITIV tail small be.PRES.3M FOC=he two in qaybiyay divide.PAST.3M

'As the sheep were shrinking in number (daba yar yahay 'the tail is small' is idiomatic for 'to shrink in number'), he divided (the flock) into two parts...' [Ciise 1985:65]

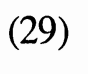
Arigi
sidii
buu
$u$ le'anayay

sheep=M.ANPH.SUBJ way=F.ANPH FOC=he in die.PROG.PAST.3M

'(Even) so, the sheep were (still) dying in that way' [Ciise 1985:65]

Focus on an adverbial is the "neutral" solution whenever attention is upon the development of the action. It is also common, together with the presentational, event-reporting use of subject focus, for the initial sentence of a text, as in (30).

(30) Maalin baa nin socota ahi, shabeel waddada day FOC man traveller be.PAST.3M.SUBJ leopard road=F.ART dhex bilqan ku kulmay middle spread in meet.PAST.3M

'One day, a traveller came by a leopard lying on the road' [Ciise 1985:69]

The default value of the focalization on an adverbial element is best seen where both a subject and an object NP are available but, being already activated, focus falls on the adverbial, as in (31).
(31)

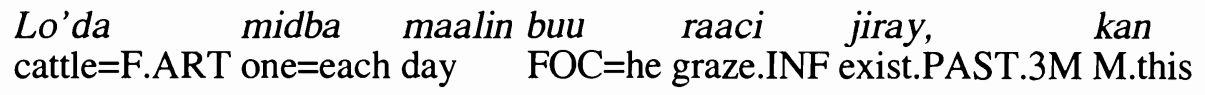 kalana qaraab buu dooni jiray other=and fruit $\quad F O C=$ he look-for.INF exist.PAST.3M
'Every day one of them was taking the cattle to pasture, while the other one was looking for edible fruits' [Ciise 1985:75]

Actually, whenever a dependent clause is present it is the rule for it to be marked by focus. In this case the focus marker also has an evident clause-demarcating role, whereby it marks the end of the dependent clause and introduces the main clause. Consider the sentences in (32) and (33).

Thus, focus marking on a sentence-initial adverbial or dependent clause shows yet another central value of focus in Somali: its use as an action-enhancing and coherence-building device. 
(32) Markii ay u caddaatay [...], buu calaacal iyo time $=\mathrm{M}$.ANPH it to become-clear.PAST.3F FOC $=$ he complaint and Alla eedeyn billaabay

God blame.VN begin.PAST.3M

'When it became obvious to him [...], he started complaining and blaming God' [Ciise 1985:65]

(33) Markuu dibi maddobe ka laacay buuna time $=\mathrm{M}=$ he bull black from finish_off.PAST.3M FOC=he=and aydii isaga guuray forest=F.ANPH just=from leave.PAST.3M

'As he had finished off the black bull, he just left the forest' [Ciise 1985:71]

\section{Clefts}

As Ajello [1995] has pointed out, it is not strictly true that only one element may be focalized in any Somali sentence: a focus marker may co-occur with a cleft. Clefts in Somali are built around waxa or waxaa, from the noun wax 'thing' 9 Actually, it is very common to have a focus-marked adverbial immediately followed by the cleft, especially at the beginning of a text, as in (34)-(36).

Waa baa waxaa belo isugu faanay libaax, good time FOC what dangerousness he.SUBJ boast.PAST.3M lion viper iyo habar and old_woman

'Once a lion, a viper, and an old woman were boasting their own dangerousness' [Ciise 1985:37]

(35) Beri baa waxaa sheekeystay hal, sac iyo ri day FOC what chat.PAST.3M she_camel cow and goat 'One day a she-camel, a cow, and a goat were chatting' [Ciise 1985:41]
Waa baa waxaa jiri
jiray
nin fulay ah

time FOC what exist.INF exist.PAST.3M man coward be

'Once there was a certain coward' [Ciise 1985:45]

9 waxa is wax followed by the article; waxaa is generally interpreted as either wax or its articulated form waxa followed by the cliticized form of the focus marker baa: wax(a) baa $\rightarrow$ waxaa, although an alternative interpretation could be as wax followed by the distal demonstrative ('that thing'). The problem with this interpretation is that in this case the constraint against a focus marker appearing more than once in the same sentence would be violated. waxa and waxaa seem to be used interchangeably. Both forms will be glossed here with 'what'. 
Clefts are generally treated as synonymous with focus sentences, and as a stylistic device used in order to bring a costituent (esp. a long, heavy one) after the verb [cf. Saeed 1987:214]. The usefulness of clefts in order to avoid embedding a long sentence before the main verb is particularly evident in (37), still another initial sentence of a folktale.

(37) Waa baa waxaa wada socdaalay afar nin oo mid fulay day FOC what together travel.PAST.3M four man and one coward yahay, mid geesi yahay mid caaqil yahay, midna be.PRES.3M one hero be.PRES.3M one smart be.PRES.3M one $=$ and kasmo iyo waaya-aragnimo isku biirsaday wisdom and experience $\quad$ REFL $=$ in accumulate.PAST.3M

'One day four men were traveling together: a coward, a hero, a trickster and one possessing both wisdom and experience' [Ciise 1985:43]

Clefts are probably more common in written than in oral styles, and are especially frequent in modern prose. A press release starts with (38).

(38) Shalay ayaa hoteel Global waxaa isugu yimid qaar yesterday FOC hotel Global what REFL=to=in come.PAST.3M part $k a \quad m i d$ ah xubnihii ka tirsanaan jiray from one is members=M.ANPH from be-part-of.INF exist.PAST.3M isbahaysigii SSA organization=M.ANPH SSA

'Yesterday a group composed of members of the organization "Somali Salvation Alliance" have met at the Global Hotel...' (www.ayaamaha.com/News/April10217/N001.html)

Syntactically, there is no problem with a cleft following a focus marker because the cleft is formally built as a relative clause ('the thing that...'), and the constraint against two focus markers occurring within the same sentence is therefore upheld. If not for the thetic value of subject focus, it seems impossible to discover a pragmatic difference between the focalization on the subject in (21), repeated below as (39), the possible use of a cleft in (39a), or, still, the focus on the time adverbial in (39b).

(39) Nin baa waa ari badan lahaa

man FOC time sheep many have.PAST.3M

'Once a man had many sheep', or

'There was once a man who had many sheep' [Ciise 1985:65] 
(39) a. Waa nin waxaa lahaa ari badan
time man what have.PAST.3M sheep many

(39) b. Waa baa nin ari badan lahaa time FOC man sheep many have.PAST.3M

The same applies to many other text-opening sentences in which subject focus is used, although an additional factor which comes into play is, of course, the use of focus in order to mark the most salient, or unexpected element. In (40), focus on the subject, stressing the fact that in former times the owner of the cows was the hyena, prepares the scene for the story, which is about how it came to be that mankind tricked the hyena and got the cattle.
Waagii hore lo'da
dhurwaa baa lahaan jiray
time=M.ANPH before cows=F.ART hyena FOC have.INF exist.PAST.3M
'Once upon a time the cows belonged to the hyena'
[lit.: 'the hyena had the cows', i.e., 'it was the hyena who had the cows'; Ciise 1985:21]

Likewise, in (41) a nominal predicate is focalized, instead of either the subject or the adverbial, because it contains the main piece of information, namely the fact that, at one time, the tortoise did not have its shell-thus setting the scene for telling how it came to get one.
Waagii
hore diinku
hilib guduudan buu
time $=$ M.ANPH before tortoise $=$ M.ART.SUBJ meat red $\quad$ FOC $=$ he
ahaa
be.PAST.3M

'Once upon a time the tortoise was (just) red meat'

[i.e., it did not have its shell; Ciise 1985:17]

\section{Avoiding focus: waa-sentences}

Up to this point, the verbal focus marker or declarative classifier waa has been left out of consideration. As mentioned above, Gebert [1986:50] notes that Somali speakers tend to avoid the use of waa when more than one NP are available; as noted by Ajello [1995:14], waa is mainly restricted to two sentence types:

1. nominal predicates, for which the use of waa before the predicate noun is mandatory, unless the nominal itself is focused (as in (41) above);

2. with intransitive verbs (but not if the sentence is event-reporting or thetic, in which case, as shown in Sections 2 and 3 above, subject focus will be used). 
The sentence in (42) provides an example of a complex nominal predicate introduced by waa.

(42) Jamhuriya waa jariidada kaliya ee xaalada

Republic waa newspaper=F.ART only LINK situation=F.ART

wadanku uu marayo ka hadasha10

country=M.ART.SUBJ it pass.PROG.DEP.3M on speak.PRES.3F

"'Republic' is the only newspaper which speaks about the situation of the country' (lit. "the situation which the country is passing")

[www.jamuriya.com]

In (43) one can note that a time adverbial ('the dry season', 'the rainy season'), although available and a good candidate for focus on the basis of what was observed in Section 5, fails to attract focus. Here the time adverbials cannot fulfil their dynamicizing role in the plot: there is no action, and a timeless condition (the behavior of the frogs) is described. This is evident if one compares (43) with (44), which precedes it in the original. In (44), focus on the time adverbial is further justified contrastively: this sentence is found after another sentence in which the man had tried in vain to get back what he has lent to the frog during the dry season.

(43) Rahu

jiilaalkii waa deyn doon

frog=M.ART.SUBJ dry-season=M.ANPH waa debt look-for

gugiina waa waalan yahay

rainy_season=M.ANPH=and WAA crazy be.PRES.3M

'During the dry season the frog wants to borrow, and during the rainy season it is crazy (for the joy)' [Ciise 1985:31]

(44) Gugii dambe ayaa misana ninkii $u$

rainy_season=M.ANPH after FOC again man=M.ANPH.SUBJ to

yimid

come.PAST.3M

'In the following rainy season the man went again to him [the frog]' [Ciise 1985:31]

Also, the examples of waa in topic-comment intransitive clauses in which the subject fails to get focus are very numerous. The sentences in (45)-(47) are three examples. In all these cases the subject has already been introduced and does not need activation, nor is it used contrastively. Furthermore, no other NPs (possible

10 The spelling used in this source is at times idiosyncratic or downright faulty; a more common spelling would be: Jamhuuriya waa jariidadda keliya ee xaaladda waddanku... 
recipients of focus) are available in (46) and (47); in (45), which is taken from the same text of (40) above, one could have found the focus on the subordinate clause, as in (48). This could also be construed as a contrastive focus (in opposition to a hypothetical situation in which hyenas disappear and the fighting between hyenas and humankind ends: 'this fighting still goes on, and it will go on UNTIL there will be the hyena').
Dagaalkii
weli wuu
socdaa,
wuuna

fight=M.ANPH.SUBJ still WAA=he go.PRES.3M WAA=he=and

soconayaa

inta waraabe jiro

go.PROG.PRES.3M until hyena exist.DEP.3M

'This fighting still goes on, and it will go on as long as there will be the hyena' [Ciise 1985:21]

(46) Kolkii la wareersaday, baa mid soo jeediyay [...] time=M.ANPH IMP confuse.PAST.3M FOC one VENT propose.PAST.3M kalase wuu diiday other=but WAA=he refuse.PAST.3M

'When they became dizzy (from hunger), one of them proposed [...], but the other one refused' [Ciise 1985:33]

(47) Caasigii wuu koray, wuu guursaday stubborn=M.ANPH.SUBJ WAA=he grow.PAST.3M, WAA=he marry.PAST.3N 'The stubborn [boy] grew and married' [Ciise 1985:59]

(48) inta waraabe jira buuna soconayaa until hyena exist.PRES.3M.FOC FOC=he=and go.PROG.PRES.3M

The same conditions apply for the use of waa in transitive sentences, as in (49). Here the attention is brought upon the hostility and lack of trust, rather than on the birds, the object of hostility. Furthermore, a possible contrastive interpretation of the object is not possible ('he does not trust THE BIRDS').

wacadkii

ma jebin,

oo haadda

weli

ringed_plover promise=M.ANPH NEG break.NEG and birds=F.ART still

wey colaadisaa

WAA $=$ she be-hostile-to=PRES.3F

'The ringed plover (a sp. of bird) did not break its promise, and it still does not trust the (other) birds' [Ciise 1985:25]

The folktale which starts with (41) above is about how the tortoise got its shell. Adam, in order to please Eve, orders the raptors to bring him the tortoise's liver. 
The tortoise overhears Adam's order and asks for God's protection, whereby God covers the tortoise with a shell. In (50), the sentence in which the tortoise hears Adam's order is not focalized because it is not going to be the topic of the following portion of text, which rather deals with the tortoise reaction at hearing the order.

(50) Diin wuu maqlayay amarka adag oo Aadan tortoise WAA=he hear.PROG.PAST.3M order=M.ART hard and Adam bixiyay, isagoo oohin iyo Alla tuug isku issue.PAST.3M he=and crying and God begging together deraya buuna nagaar hoosta ka mix.PROG.PRES.3M.FOC FOC=he=and bush under=F.ART in galay... enter.PAST.3M

'The tortoise heard the harsh order given by Adam, and, crying and asking for God's protection, sought refuge under a bush' [Ciise 1985:17]

The example in (51) is a coordinated sentence from a well-known tale in which the jackal tricks the crocodile out of his tongue; the jackal (dawo) is not focalized because attention is directed toward the consequences of the crocodile trusting him.

(51) Yaxaas dawo wuu aaminay carrabkiina wuu crocodile jackal WAA=he trust.PAST.3M tongue=M.ANPH=and WAA=he siiyay give.PAST.3M

'The crocodile trusted the jackal and gave him his tongue' [Ciise 1985:29]

\section{An excursus on noun incorporation and its pragmatic value}

The tale about the crocodile's tongue introduced in (51) ends with (52), another coordinated sentence. Compare the last clause in (52) with two possible alternatives, (52a) and (52b). The sentence in (52a) has object focus: no contrast with another object is implied, and it is grammatically possible but pragmatically odd,

(52) ... dawo webi kama ag dhowaato, yaxaasna jackal.SUBJ river to=not near approach.NEG.3M crocodile.SUBJ=and

wuu weli carrab la'yahay

still WAA=he tongue miss.PRES.3M

'.. the jackal still does not go near a river, while the crocodile still does not have his tongue' [Ciise 1985:29] 
(52) a. yaxaasna weli carrab(kii) $\quad$ buu la'yahay
crocodile.SUBJ=and still tongue(=M.ANPH) $\mathrm{FOC}=$ he miss.PRES.3M

(52) b. yaxaasna weli carrab(kii) wuu la'yahay crocodile.SUBJ=and still tongue $(=\mathrm{M} . \mathrm{ANPH}) \mathrm{WAA}=$ he miss.PRES.3M

as the tongue is topical (it is the element around which the tale turns, and in order to be fully acceptable, in (52a) carrab should be made definite and referential with an article or a possessive).

More difficult is to ascertain the eventual pragmatic difference between (52) and (52b) (where, again, carrab should be definite and referential). In (52b) all the NPs are placed outside of the Verbal Complex wuu la'yahay. The original sentence, (52), shows instead noun-incorporation of the object (carrab) into the verb; carrab la'yahay could well be written carrabla'yahay or, even, carrabla' yahay and (52) could be aptly translated 'the crocodile is still tongueless'.

We cannot deal here with the whole complex question of noun incorporation in Somali (preliminary observations can be found in Sasse [1984] and Ajello 1995]), and we limit ourselves to pointing to its pragmatic role in text building. Noun-incorporation is, in Somali, first of all a widely used lexical device in order to enrich the vocabulary [cf. Caney 1984]; it yields innumerable new verbs and nouns, from sinjifaquuq 'to discriminate because of race' (from sinji 'race' and faquuq 'to separate') to jawrfal 'to oppress' (from jawr 'tyranny' and fal 'to do'). But noun-incorporation is also a productive device in everyday speech; through noun incorporation one can background, detopicalize an element in the sentence. To come back to the pragmatic difference between (52) and (52b): (52b) would probably be uttered whenever the attention is brought upon the action, rather than upon a topical object (as in (52) above). But in (52), the last sentence of the text, the crocodile's tongue is no longer a topic; rather, the crocodile's fate and its current situation is. What the crocodile does not have is not just its tongue, but any tongue; it has become a tongue-less animal, and the tale is about how this came to happen. An incorporated noun is indeterminate and non-referential, and carrab appears here without any determiner, be it the determinate article (carrabka), the anaphoric article (carrabkii) or a possessive (carrabkiisa 'its tongue'). 11

One therefore finds in Somali a tripartite opposition in the pragmatic marking of elements:

1. focus-marked (either through a focus marker or clefting);

2. topical (not-focus-marked, out of the Verbal Complex);

3. detopicalized, backgrounded (incorporated in the verb).

11 There are actually a few cases in which a noun is incorporated together with the article; an example is farta fiiq as an alternative to farfiiq 'to point out, indicate' ("to point [the] finger"). The form with the definite article is always written separated from the following verb, and informants seem to have problems in accepting sentences with it, generally preferring farfiiq. 


\section{A verbal focus? Pragmatic and comparative notes on waa}

The problem with waa-sentences is to understand whether the attention towards the action evidenced in Section 7 is a positive feature of waa or simply a consequence of the absence of focus on a nominal constituent. Saeed makes a similar point when he notices that "[T] can be contrasted nor that waa sentences are compatible with verbs being introduced as new information. The problem arises when waa is seen as a syntactic device reflecting this" [Saeed 1984:179].

Although a great amount of effort has been deployed to save the analysis of waa as a verbal focus particle (originally introduced by Andrzejewski [1975]; cf. also Svolacchia, Mereu \& Puglielli [1995]), it seems to the present writer that Saeed's original arguments (based among others upon the behavior of waa and the focus particles in negative, interrogative and coordinated sentences) still hold much of their value. The following observations are meant to support, from a pragmatic and functional point of view, Saeed's syntactic analysis of waa as "something else" than a focus particle.

First of all, the use of waa in intransitive sentences is obviously in opposition to the focalization of the only other element in the clause, namely the subject. Let us compare (53) and its near-synonym (54) (without the subject pronoun -uu cliticized to waa, on which see below) with (55).

(53) Cali wuu yimid

Cali.SUBJ WAA=he come.PAST.3M

'Cali came'

(54) Cali waa yimid

Cali.SUBJ WAA come.PAST.3M

'Cali came'

(55) Cali baa yimid

Cali FOC come.PAST.3M.FOC

'CALI came'

In (53) and (54) the possible focus on the verb ('Cali CAME') is an automatic consequence of the absence of subject focus. In English, the pronunciation 'Cali CAME' is phonologically the only alternative to 'CALI came'. Pragmatically, it is consistent both with a broad focus interpretation, as in

i. 'What did Cali do?' _ _Cali CAME'

and with a narrow focus on the verb, as in:

ii. 'Did Cali stay home?' - '(No,) Cali CAME' 
Likewise in Somali: case (i.) was seen above as (20), repeated here as (56). Case (ii.) would correspond in Somali to (57), which could be answered by a variant of (53), shown in (58).

(56) Cali muxuи sameeyay?

Cali.SUBJ what $=$ he do.PAST.3M

'What did Cali do?'

(57) Ma Cali gurigiisa joogay?

Q Cali.SUBJ house=M.his stay.PAST.3M

'Did Cali stay home?'

(58) Maya, Cali wuu yimid

no Cali.SUBJ WAA $=$ he come.PAST.3M

It was seen in Section 2 that an answer with subject focus is required by an argument-focus question, such as that in (59).

(59) Yaa yimid?

who come.PAST.3M.FOC

'Who came?'

(60) Cali baa yimid

Cali FOC come.PAST.3M.FOC

'CALI came'

It was also noted that subject focus is likewise acceptable in the case of an eventreporting sentence with a transitive verb and an overt object, as in question (1) and its answer (2), repeated here as (61) and (62), respectively.

(61) Maxaa dhacay?

what happen.PAST.3M.FOC

'What happened?'

(62) Cali baa Maryam dilay

Cali FOC Maryam beat.PAST.3M.FOC

'Cali beat Maryam'

Subject focus is scarcely acceptable with an intransitive verb: (63) is odd as an answer to (61); in its place, (53) could be used. Note that in (53) (as well as in (2) in Section 2) the subject is topical, and (53) could also be used as a reply to (20), repeated here as (64). In Section 2 (20) was answered with (21), repeated here as (65). 
(63)

??Cali baa yimid

Cali FOC come.PAST.3M.FOC

'CALI came'

(64) Cali muxuu sameeyay?

Cali.SUBJ what=he do.PAST.3M

'What did Cali do?'

(65) Cali Maryam buu dilay

Cali.SUBJ Maryam FOC=he beat.PAST.3M

'Cali beat Maryam'

As for (53) and (54), Gebert [1986:60] has pointed out that, although both are grammatically correct, they are not exactly synonymous pragmatically: (53) is consistent with a more topical subject, while (54) [which Gebert proposes to translate as 'Cali did come'] is preferred if no subject was mentioned and more information is going to follow: in (54), 'the truth value of the event expressed by the verb [...] is asserted with more intensity' than in (53), so that (54) 'appears as more marked for the focus of assertion on the verb' than (53). Moreover, a sentence such as (53) "can be uttered in a context announcing a new state of affairs; it is considered thus as an unmarked sentence"; a sentence such as (54), on the other hand, "can apparently be used as an announcement (confirmation) of an expected event" and "cannot be uttered in isolation, but has to be followed by some other sentence. It functions, then, as a beginning of a story" [Gebert 1986:61]. All in all, (54) is "preceived as a marked pattern", while (53) is unmarked. Moreover, as remarked by Gebert [1986:62], the topical value of the subject pronouns is further confirmed by their behavior with the focus particles, whereby they are precluded from appearing with subject focus; for example, while (2) above (repeated here as (66)) is correct, its variant (67) is ungrammatical.

(66) Cali baa Maryam dilay

Cali FOC Maryam beat.PAST.3M.FOC

'Cali beat Maryam'

(67) *Cali buu Maryam dilay

Cali FOC=he Maryam beat.PAST.3M.FOC

'Cali beat Maryam'

In general, our informants confirm Gebert's analysis (although it must be stressed again that informants tend to give different acceptability values to waasentences in general). Now, given that waa is present in both sentences and the only difference between (53) and (54) is given by the absence in the latter of the subject pronoun -uu, whose presence alone gives to (53) "a more topical value", it stands to reason to assume that "the focus of assertion on the verb" (to use 
Gebert's formulation) is not given by waa, but by the absence of a topical subject. That is, the focalizing value of waa is essentially illusory and the result more of the absence of baa/ayaa than of any specific value of waa itself.

If waa is not a focus particle, what is it? One must confess that Saeed's "declarative particle" hypothesis is not very convincing: typologically, it is unusual (although not unattested) for a language to mark the most unmarked sentence type, the declarative sentences, with a specific particle (especially if this particle has no further functions, such as marking evidentiality). Even in the Somali-speaking context, waa is an absolute isolate.

In very broad terms, one can distinguish within Somali between a NorthernCentral dialect cluster and a much more heterogeneous group of Southern dialects (possibly separate languages in strictly linguistic terms). In the distribution we have seen, waa is restricted to Northern Somali (and the official language upon which it is based); already in the closely related Central varieties [the "Benaadir" dialects in Lamberti's 1986 classification] its place in nominal sentences is taken by the sentence-final copula waaye or weeye; cf. (68), which is acceptable in writing, although distinctly marked as "Southerner", and (69), its Northern variant.

(68) run waaye (or weeye)

truth COPULA

'it is true'

(69) waa run

WAA truth

In the Southern Somali dialects (the Maay, Ashraaf and Digil groups of dialects, following Lamberti's classification), waa is unknown. These varieties, moreover, have no obligatory focus marking, and a sentence without focus is fully acceptable and indeed the normal solution. At the same time, these dialects make probably a much wider use of clefts as a focalizing device (cf. Tosco [1997] for the Tunni dialect and Tosco [1993] for an overview of Southern Somali focus and cleft constructions). The same final position of the copula found in the Central varieties is the rule in all the Southern dialects; in Tunni, one finds (70) for (69) of Northern-Central Somali.

(70)

$$
\begin{aligned}
& \text { rún=u} \\
& \text { truth }=\text { COPULA }
\end{aligned}
$$

In verbal sentences, waa is found in front of the verbal complex in the Central dialects just as in the Northern dialects and in the written language. But in the Central dialects, although much relevant data is lacking, it seems that the use of the subject pronouns is restricted if not absent; one finds, e.g., (71) for Standard Somali (72). 
(71) waa ni arkey

WAA you.P see.PAST.1S

'I saw you (P)' (Xamari dialect of Mogadishu [Lamberti 1986:59])

(72) waan idin arkay

WAA=I you.P see.PAST.1S

It seems evident, on comparative and typological grounds, that the shift of the copula from sentence-final (as is normal in verb-final language) to preverbal position was a Northern-Central innovation, whose reasons are unclear. It is possible that the necessity to unambiguously distinguish main and relative clauses played a role: as Somali lacks relative pronouns, the main feature of relative (and dependent clauses in general) is the absence of either a focus particle or waa (although a supplementary feature is provided by a different tonal pattern on the verb and, in certain syntactic contexts, a segmentally different verbal form). In the absence of waa, a focusless sentence in which the Verbal Complex follows immediately an NP could be interpreted as a relative clause. Compare, for example, (47) above, partially repeated here as (73), and the relative clause in (74) (whose verb has a different tonal pattern). From this position after an unfocused NP, waa could have later been generalized to all declarative unfocused sentences.
Caasigii
wuu koray $[\ldots]$

stubborn=M.ANPH.SUBJ WAA=he grow.PAST.3M

'the stubborn [boy] grew and married' [Ciise 1985:59]
(74) [Caasigii koray] baan jeclahay
stubborn=M.ANPH grow.PAST.3M FOC=I like.PRES.1S
'I like the stubborn [boy] who grew'

The Southern Somali dialects also do not have the subject pronouns we have seen in most sentences in this article, which in main sentences are cliticized to the focus particles baa or ayaa or to waa, yielding such forms as baan (from baa + -aan 'FOC=I'), wuu (from waa + -uu 'he'), etc. For disambiguating purposes, the independent pronouns may be used, but they are not mandatory, and, since neither a focus particle nor a subject pronoun is necessary, (75) is a perfectly accettable sentence in Tunni, corresponding in Standard Somali (in this context) to (76).
(75)
débkíi soo qáadi
fire=M.ANPH VENT take.PAST.3M
'he took up the fire' [Tosco 1997:81]

(76) dabkii wuu soo qaaday

fire=M.ANPH WAA=he VENT take.PAST.3M 
Now, while the subject pronouns of Northern Somali are often written as separate words in certain syntactic environments, in speech they normally cliticize; in relative clauses (which have no focus marking; cf. Section 1), they cliticize to the head noun, although they are generally written as separate words. An example is the relative clause in (77), which is normally pronounced (and sometimes also written) as (78).

(77)

guriga aan lacagtii ka keenay house=M.ART I money=F.ANPH from bring.PAST.1S 'the house out of which I brought the money' gurigaan $\quad$ lacagtii
house=M.ART=I money=F.ANPH from bring.PAST.1S

In a similar context, a Southern dialect would rather use an independent subject pronoun, as shown in (79) for Tunni.

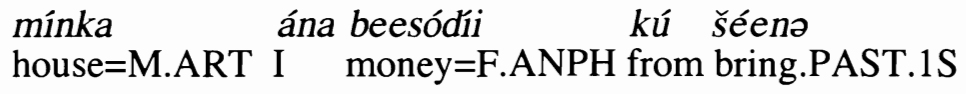

After the shift of waa to preverbal (or better: pre-Verbal Complex) position in focusless declarative sentences, the cliticization of the subject pronouns to it was the logical next step. Also the slight difference between the use of the subject pronouns in certain waa-sentences (cf. (53) and (54) above) is possibly a sign of an on-going change and the result of different dialect influences, as shown by the absence of the subject pronouns with waa in certain Central dialects (cf. (68) above).

\section{Conclusions}

We have seen that in Somali there is no correspondence between the linguistic expression of focus and its pragmatic value. Using Lambrecht's [1994] classification of focus constructions, one may summarize the situation in Somali as follows:

1. ARGUMENT FOCUS is typically expressed by the focus particle following (or cliticized to) the relevant NP, or by a cleft;

2. SENTENCE FOCUS is generally expressed by focus on the subject, except when no overt NP is available, in which case a focus-unmarked sentence with waa and no subject pronouns may be used;

3. PREDICATE FOCUS, being the unmarked case, may find different expressions:

a. argument-focus on an NP, generally along the following implicational scale: $\mathrm{ADV}>\mathrm{OBJ}>\mathrm{SUBJ}$;

b. a focus-unmarked sentence with waa;

c. a cleft. 
It has also been argued that the element waa which appears as a copula in nominal sentences is not, pragmatically speaking, a focus particle, thereby confirming Saeed's [1984 and following] syntactic analysis.

Possibly the most important point has to do with the vexata quaestio of the focus particles and their role. It is evident that to call baa and ayaa "focus markers" is at best an oversimplification. As soon as one leaves the question-andanswer framework upon which much syntactic work has been based and looks at actual Somali texts, it becomes apparent that focus (at least in its narrow, conventional meaning) is just one, and possibly not even the most prominent nor common, function of these particles. In fact, their use as topic-switching and action-enhancing devices is central in text-building. Given this wide variety of functions, it would probably be safer to label baa and ayaa simply as "foregrounding particles".

\section{REFERENCES}

Ajello, Roberto. 1995. "La focalizzazione in somalo". In Roberto Ajello and Saverio Sani (eds.), Scritti linguistici e filologici in onore di Tristano Bolelli. Pisa: Pacini. Pp. 1-28.

Andrzejewski, Bogumil W. 1964. The Declensions of Somali Nouns. London: School of Oriental and African Studies.

Andrzejewski, Bogumil W. 1975. "The role of indicator particles in Somali". Afroasiatic Linguistics 1/6:1-69.

Caney, John Charles. 1984. The Modernisation of Somali Vocabulary with Particular Reference to the Period from 1972 to the Present. Hamburg: Helmut Buske.

El-Solami-Mewis, Catherine. 1980. "Zur Rolle der Satzpartikeln beim Ausdruck des logischen Prädikats im affirmativen Somalisatz". Zeitschrift für Phonetik, Sprachwissenschaft und Kommunikationsforschung 33,2:185-196.

El-Solami-Mewis, Catherine. 1981. "Zum Stand der Diskussion über die Rolle der Satzpartikeln im Somali”. Zeitschrift für Phonetik, Sprachwissenschaft und Kommunikationsforschung 34,1:10-16. 
Gebert, Lucyna. 1986. "Focus and word order in Somali". Afrikanistische Arbeitspapiere 5:43-69.

Hetzron, Robert. 1965. "The particle baa in Northern Somali". Journal of African Languages 4,2:118-130.

Lamberti, Marcello. 1986. Die Somali-Dialekte. Hamburg: Helmut Buske.

Lambrecht, Knud. 1994. Information structure and sentence form. Cambridge: Cambridge University Press.

Lecarme, Jacqueline. 1994. "Focus et effets "verbe second" en Somali". Recherches Linguistiques de Vincennes 23:25-44.

Puglielli, Annarita. 1981. "Frase dichiarativa semplice”. In Annarita Puglielli (ed.), Sintassi della lingua somala. Roma: Ministero degli Affari Esteri, Dipartimento per la Cooperazione allo Sviluppo. Pp. 1-44.

Saeed, John Ibrahim. 1984. The Syntax of Focus and Topic in Somali. Hamburg: Helmut Buske.

Saeed, John Ibrahim. 1987. Somali Reference Grammar. Kensington, MD: Dunwoody Press [Second Revised Edition: 1993].

Saeed, John Ibrahim. 1999. Somali. Amsterdam: John Benjamins.

Sasse, Hans-Jürgen. 1984. "The pragmatics of noun incorporation in Eastern Cushitic languages". In Frans Plank (ed.), Objects: Towards A Theory Of Grammatical Relations. London: Academic Press. Pp. 243-268.

Svolacchia, Marco, Lunella Mereu and Annarita Puglielli. 1995. "Aspects of discourse configurationality in Somali”. In Katalin É. Kiss (ed.), Discourse Configurational Languages. New York: Oxford University Press. Pp. 65-98.

Tosco, Mauro. 1993. "Copula, focus, cleft, etc. in Southern Somali". Afrikanistische Arbeitspapiere 36:77-96.

Tosco, Mauro. 1997. Af Tunni. Grammar, Texts and Vocabulary of a Southern Somali Dialect. Köln: Rüdiger Köppe. 
Somali texts and websites used in the analysis:

Ciise Maxamed Siyaad. 1985. Favole somale. Roma: Ministero degli Affari Esteri, Dipartimento per la Cooperazione allo Sviluppo.

www.ayaamaha.com

www.jamhuriya.com

Università di Napoli "L'Orientale"

[Received May 2002;

Dept. of African and Arab Studies accepted November 2002]

I-80134 Napoli

Italy

m.tosco@iuo.it 
